\title{
The Exploration and Analysis of Completion Rate and Efficiency Rate of MOOC Based on Data Analysis_-Taking Ancient Chinese Architectural Art as an Example
}

\author{
Lu Liu ${ }^{a}$, Rensheng $\mathrm{He}^{\mathrm{b}}$ Mengqiu Cai ${ }^{\mathrm{c}}$ \\ School of Physics and Electronics, Hunan University, Changsha 410000, China. \\ anaisilu@163.com, b1017320606@qq.com, c22700057@qq.com
}

Keywords: MOOC, completion rate, efficiency rate, data analysis.

\begin{abstract}
Compared to completion rate, efficiency rate is learning efficiency of MOOC study. It's not irrelevant to if learners can complete the tests and examinations but emphasize the amount of knowledge of migration. Based on the researches before, the study constructs evaluation index system and analysis mode of completion rate and efficiency rate, and empirically analyzes academic records and interaction by using the method of data analysis, collecting related background datum to analyze and assess the completion rate and efficiency rate of the learners, basing on ancient Chinese architecture art. To offer the pertinence suggestions for evaluate learners' achievements on MOOC, in order to promote the correct understanding of learners' achievement.
\end{abstract}

\section{Introduction}

The completion rate is the number of students who pass the exam in percentage of the total number of students who register the course. The low completion rate of MOOC has been deeply valued, and the research on it has developed into a new normal. Many researchers have investigated and studied on the completion rate of MOOC, the main researches focus on the following three categories: 1) Rate courses' completion rate by acquiring learners' learning behavior data and take it as a touchstone of the quality of the course and learners' learning outcomes [1].2) Analyze the causes of the high exit rate from learner's educational backgrounds, learning characteristics, background technical support, and curriculum setting [2]. 3) Discuss the development of MOOC from concept, evaluation paradigm, potential, society, system, technology, market and modeling, and try to solve the phenomenon of the low completion rate [3].

The efficiency rate is the learning efficiency when study MOOC. It has nothing to do with whether the learner has completed the required tests, but to emphasize how much knowledge the learner has migrated. In other words, the completion rate focuses on results, while the efficiency rate values on processes. The concept of efficiency rate was first proposed by the Taiwan scholar Zhao Hong Liao in 2014[4]. He holds the point that the core of Enterprise MOOC is the efficiency rate rather than the completion rate. He proposed that if a course worries about how to improve the completion rate, the best solution is to prohibit students who lack persistence registering. However, if not everyone can take courses as they wish, MOOC will lose the original meaning. Although the theory is unique, there are some defects, for instance, lacking data analysis, representation and so on.

Therefore, the study absorbs the concept of efficiency rate, constructs evaluation index system, and analyzes the completion rate and efficiency rate of the learners by using the method of data analysis and collecting learning-related datum. To provide guidance and reference for the development of MOOC.

\section{The Construct of Evaluation Index System}

The completion rate is the number of students who pass the exam in percentage of the total number of students who register the course. The study takes the completion grade, including unit test, unit and final exam, as evaluation index items of the completion rate. 
The efficiency rate is the number of students who pass the discussion exam in percentage of the total number of students who register the course. The study takes the efficiency grade, including the number of posts, number of replies, number of comments, number of be thumbed up as evaluation index items of the efficiency rate, the weights of the indicators are measured by the questionnaire. The evaluation index system of the completion rate and the efficiency rate of MOOC is shown in Table 1.

Table 1 the evaluation index system of the completion rate and the efficiency rate

\begin{tabular}{|c|c|c|c|}
\hline target layer & $\begin{array}{l}\text { first class } \\
\text { indicator }\end{array}$ & $\begin{array}{l}\text { second } \\
\text { class indicator }\end{array}$ & indicator characterization \\
\hline \multirow{2}{*}{$\begin{array}{l}\text { completion } \\
\text { rate }\end{array}$} & \multirow{2}{*}{$\begin{array}{l}\text { completion } \\
\text { grade }\end{array}$} & unit test & $\begin{array}{l}\text { unit test is issued every Friday over seven weeks, } \\
\text { the maximum mark is } 40 \text {; }\end{array}$ \\
\hline & & final exam & $\begin{array}{l}\text { final exam is issued in the ninth week, } \\
\text { the maximum mark is } 60\end{array}$ \\
\hline \multirow{4}{*}{$\begin{array}{l}\text { efficiency } \\
\text { rate }\end{array}$} & \multirow{4}{*}{$\begin{array}{l}\text { efficiency } \\
\text { grade }\end{array}$} & number of posts & $\begin{array}{c}\text { the total number of posts, issued by learners in the } \\
\text { learning process; }\end{array}$ \\
\hline & & number of replies & $\begin{array}{l}\text { the number of learners taking the initiative to } \\
\text { comment on an existing post or topic; }\end{array}$ \\
\hline & & number of comments & $\begin{array}{l}\text { The number of evaluations by learners in response } \\
\text { to other learners' responses; }\end{array}$ \\
\hline & & $\begin{array}{l}\text { number of be } \\
\text { thumbed up }\end{array}$ & $\begin{array}{l}\text { The number of thumb up received by the learner's } \\
\text { comments or reply; }\end{array}$ \\
\hline
\end{tabular}

\section{Design and Implementation of the Research}

\subsection{Analysis Mode of the Completion Rate and Efficiency Rate.}

As is shown in Fig.1. The completion grade of learners', which means the completion rate, can be available directly through the background data of MOOC of Chinese University. And also, the number of posts, replies, comments, and be thumbed up can be taken through the same way. The index weight of the above four indicators can be surveyed to get the efficiency rate.

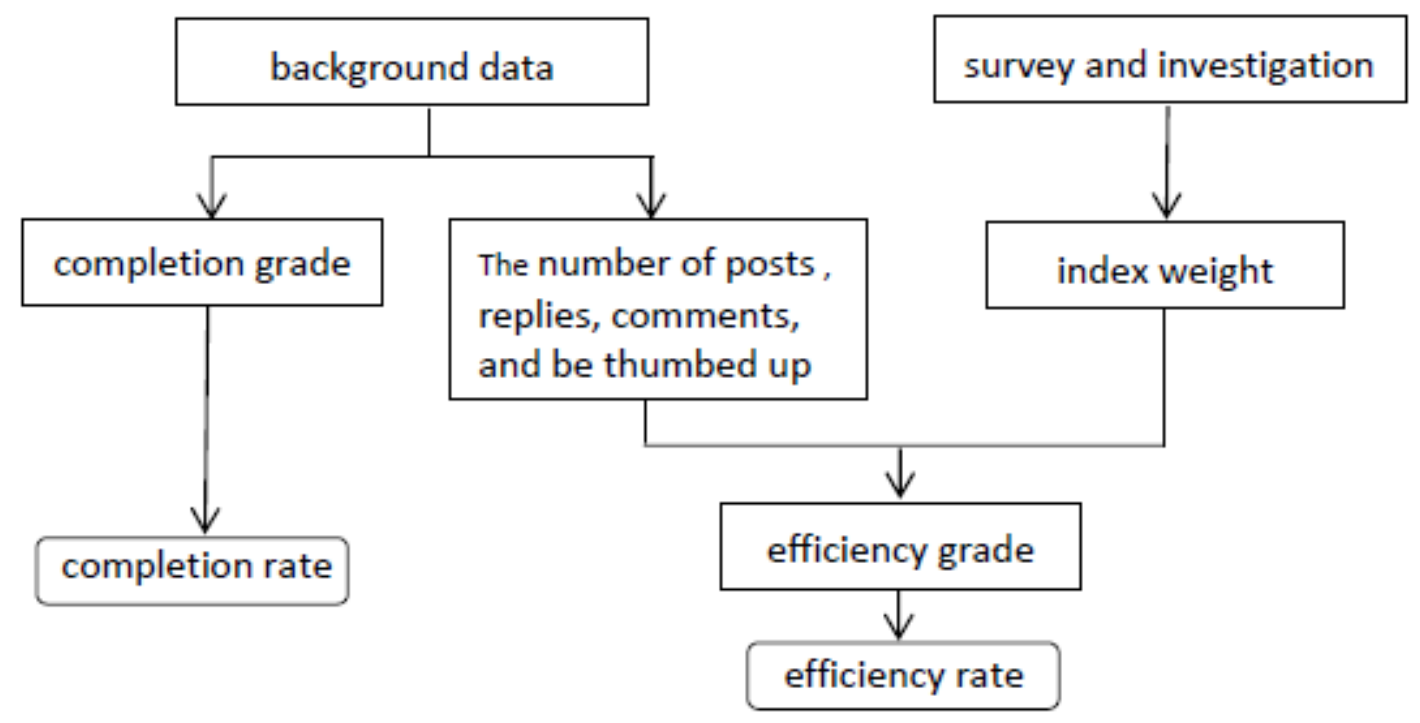

Fig.1 analysis mode of Completion Rate and Efficiency Rate

\subsection{Survey Design.}

The research was targeted at the course, ancient Chinese architectural art, which is released on the platform of MOOC of Chinese University. The open valid data set for this study includes learner's username, completion grade, the number of posts, the number of replies, the number of comments, and the number of be thumbed up. 
The object of the study questionnaire is the learners who study the ancient Chinese architectural art through the MOOC of Chinese University from November 3, 2015 to January 31, 2016. The researches send the questionnaire by mail to inform the learners to fill in, a total of 555 people filled out the questionnaire. Since filling in the questionnaire is for a minimum of 90 seconds, so the datum for less than 90 seconds was counted, and a total of 479 valid questionnaires were obtained, questionnaire efficiency was $86.31 \%$.

\subsection{Analysis of Index Weight of Efficiency Rate.}

Calculate the weight of the indicators in order to accurately calculate the efficiency rate through the statistics, as shown in Table 2.

Table 2 index weight

\begin{tabular}{ccccc}
\hline index & posts & replies & comments & be thumbed up \\
\hline weight & 0.256 & 0.257 & 0.211 & 0.276 \\
\hline
\end{tabular}

\subsection{Results and Analysis.}

The background data from the MOOC of Chinese University reveals that the total number of students on this course from November 3, 2015 to January 31, 2016 is 29099.

As for the completion grade, less than 60 points is for failing, 60 points to 84 points is for qualified, 85 to 100 points is for excellent. At the end of the course, there are 1784 learners have records of grades, of these, 451 of them were qualified, accounting for $1.55 \%, 226$ of them were excellent, accounting for $0.78 \%$. The completion rate is $2.33 \%$ (number of qualified learners + number of excellent learners) / total number of students on this course).

As for the efficiency grade, the study calculates it according to the indicators surveyed through the questionnaire, less than 1 point is for failing, 1 point to 2 points is for qualified, 2 points or more is for excellent. At the end of the course, there are 1828 learners have records of grades. 1349 of them were failed, accounting for $8.35 \%, 246$ of them were qualified, accounting for $0.85 \% .233$ of them were excellent, accounting for $0.8 \%$. The efficiency rate is $1.65 \%$ (number of qualified learners + number of excellent learners) / total number of students on this course).

\section{Summary}

The research which based on ancient Chinese architectural art, has analyzed it from the angles of completion rate and efficiency rate. The completion rate and efficiency rate is respectively $2.33 \%$ and $1.65 \%$, on the one hand, it reveals the fact that both of them are extremely low, on the other hand, it also shows that a relatively large number of learners pay attention to the results of this study, while ignoring the interaction in the learning process. It is one of the original aspirations of MOOC to transform traditional education, which is rigid and single, into modern education, which is participatory and interactive. However, it is clear that this advantage hasn't been full play. When assessing the achievement of MOOC learners, it should be measured thoroughly and personally from 2 dimensions, which are the completion rate and efficiency rate.

The study takes a course of MOOC as a research object, and mainly analyzes the macro data. In the future, we will study the multi-type courses and combine the learners' personal learning behavior data and use the methods of data mining and machine learning to conduct a more in-depth analysis of completion rate and efficiency rate, to explore deeper reasons behind their behavior, in order to improve learners' learning performance.

\section{Acknowledgements}

The key project of National Education Science Plan Ministry of Education: Influencing Factors and Optimizing Research on Independent Student Enrollment in Colleges and Universities. Fund number: DIA150297 


\section{References}

[1]. Jing Wang, Hong Xian, Lin Shi, A Study on the Learning Behavior of learners in MOOC Taking Shanghai University of Engineering and Technology as an Example, Science \& Technology Information. 34(2016)55-59.

[2]. Haigh Ye, Winged Jin, An Analysis of the Causes of the High Exit Rate of MOOC, China Educational Technology \& Equipment. 16(2015)8-9.

[3]. Daniel,J.Making Sense of MOOCs:Musings in A Maze of Myth, Paradox and Possibility, Journal of Interactive Media in Education. 2(2008)20-27.

[4]. Zhao Hong Liao, The things on Enterprise MOOC-Completion Rate VS Efficiency Rate, Distance Education in China, (2014)91-92. 